\title{
Quiste renal complejo. Tratamiento laparoscópico
}

\author{
Benejam Gual JM, Diez-Caballero Alonso F, García-Miralles Grávalos. R. \\ Servicio de Urología. Fundación Hospital de Manacor. Mallorca (Islas Baleares).
}

Actas Urol Esp 2006; 30 (6): 626-629

\section{RESUMEN}

\section{QUISTE RENAL COMPLEJO. TRATAMIENTO LAPAROSCOPICO}

La diferenciación entre los quistes renales benignos, que no requieren tratamiento quirúrgico, y aquellos que requieren exploración quirúrgica en ocasiones es difícil.

El tratamiento mediante cirugía laparoscópica (Decorticación quística - Nefrectomía laparoscópica parcial o radical según los hallazgos) se establece día a día como el tratamiento de elección en los pacientes con quiste Renal atípico o complejo Grado III y IV de Bosniak, así como en los quistes renales tipo I/II sintomáticos y en determinados pacientes con quiste renal etiquetado como IIF de Bosniak.

Presentamos un caso clínico en el que se halla carcinoma renal de células claras tras decorticación laparoscópica de un quiste Grado II de Bosniak, con realización posterior de nefrectomía radical laparoscópica.

Palabras Clave: Quiste renal. Carcinoma renal. Laparoscopia.

\section{ABSTRACT \\ COMPLEX RENAL CYST. LAPAROSCOPIC TREATMENT}

The difference between the simple renal cysts, that doesn't require surgical treatment, and those that need it, sometimes is difficult.

The laparoscopic surgical treatment (laparoscopic cyst decortication -laparoscopic partial nefrectomy or radical laparoscopic nefrectomy) its becoming the gold standard technique, recommending this procedure in Bosniak cyst type III or IV, and in the symptomatic renal cyst type I/II and in any patients with Bosniak cyst renal II .

We present a case report in which a renal cell carcinoma was found after laparoscopic cyst decortication of Bosniak cyst type II with laparoscopic radical nefrectomy posteriorly.

Key Words: Kidney cyst. Renal carcinoma. Laparoscopy.

$\mathrm{E}$ uso generalizado de la ecografia abdominal ha condicionado el aumento exponencial de la detección incidental de las lesiones renales quísticas, siendo bien definida, tras la clasificación de Bosniak, la pauta de seguimiento y tratamiento de las mismas.

Con la irrupción de la cirugía laparoscópica, como opción mínimamente invasiva de tratamiento en pacientes con quistes renales (sinto- máticos o complejos), ha cambiado la estrategia a seguir, según nuestra opinión, en aquellos pacientes en los que se detecte dicha patología, sin perjuicio de seguir las ya contrastadas indicaciones quirúrgicas propuestas según los hallazgos radiológicos (clasificación de Bosniak).

Presentamos un caso clínico que pone de manifiesto las posibilidades, a la vez que las complicaciones, de tratamiento mínimamente 
invasivo en los pacientes con quiste renal atípico o complejo revisando las pautas a seguir, en la actualidad, ante el hallazgo de un quiste renal sintomático o complejo mediante el tratamiento laparoscópico.

\section{CASO CLINICO}

Paciente mujer de 56 años con antecedentes personales de fibromialgia, síndrome depresivo e hipotiroidismo. Tras ingreso en servicio de cirugía general por colecistitis litiásica se halló incidentalmente mediante ecografía un gran quiste renal en polo superior de riñón izquierdo con septos finos en su interior, por lo que se remitió a paciente a nuestras consultas. Le solicitamos ante el hallazgo ecográfico un TAC renal preferente (Fig. 1) que nos confirmó la presencia de un quiste renal de gran tamaño (9 cm de diámetro) en el polo superior del riñón izquierdo, con múltiples pero finos septos en su interior así como alguna calcificación lineal siendo clasificado como quiste renal grado II de Bosniak, aconsejando no obstante la conveniencia de seguimiento radiológico de la paciente (con lo que se podría subclasificar como quiste renal tipo II $\mathrm{F}$ de Bosniak).

Se indicó y realizó, previa valoración anestésica, Decorticación laparoscópica. Se realizó pneumoperitoneo con aguja de Veress, seguido de colocación de 2 trócares de $5 \mathrm{~mm}$ en hipocondrio $\mathrm{y}$ fosa inguinal izquierda.

Se siguió con decorticación de quiste renal izquierdo, con salida de líquido intraquístico claro, así como fulguración del lecho del quiste. Se remitió a estudio anatomopatológico las paredes del quiste decorticado.

El curso postoperatorio trascurrió sin incidencia alguna siendo la paciente dada de alta a los dos días tras la intervención quirúrgica.

El estudio anatomopatológico del quiste cortical determinó paredes del quiste renal con aislados grupos celulares sospechosos de malignidad (carcinoma de células claras). Ante ese hallazgo se repitió TAC renal (Fig.2) donde se observa la exéresis completa del quiste renal complejo, pero ante los hallazgos anatomopatológicos se decidió la realización de nefrectomía radical laparoscópica.

Se realizó abordaje laparoscópico tras crear pneumoperitoneo con trócar de Hasson pararrec-

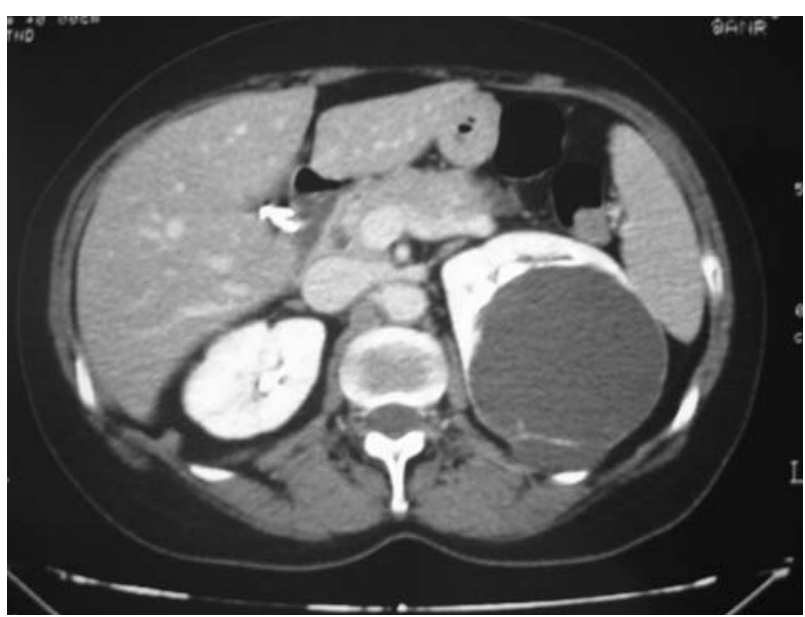

FIGURA 1

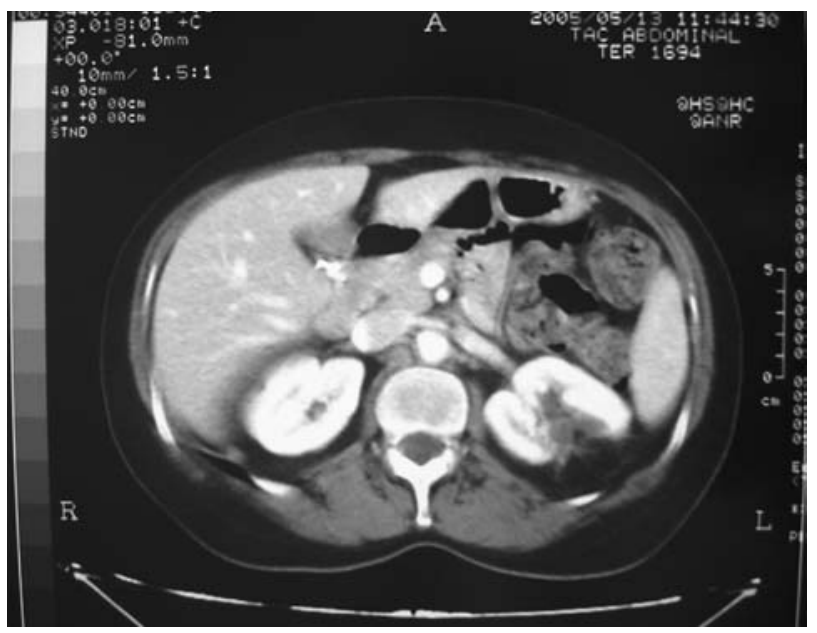

FIGURA 2

tal a nivel del ombligo seguido de colocación de 3 trócares (2 de $5 \mathrm{~mm}$ en hipocondrio y flanco y uno de $10 \mathrm{~mm}$ en fosa inguinal izquierda). Se colocaron Hemo.lock en arteria y vena renal con sección posterior de las mismas, sin apreciar gran dificultad en la disección por la realización de la cirugía previa.

El curso postoperatorio trascurrió sin incidencia alguna siendo dada de alta a los 3 días tras intervención quirúrgica.

El estudio anatomopatológico confirmó aislados nidos de carcinoma de células claras en la pared quística residual.

A los 4 meses de seguimiento tras la nefrectomía laparoscópica la paciente permanece asintomática sin signos de recidiva local o a distancia. 


\section{DISCUSIÓN}

Desde la clasificación propuesta por Bosniak en $1986^{1}$ en base a los hallazgos demostrados en el TAC ha existido más consenso en cómo tratar a los pacientes según en la categoría en la que se hallaban (Grado I y Grado II: no se debe indicar intervención quirúrgica salvo presencia de sintomatología; Grado III: En el 50\% de los casos patología tumoral asociada por lo que se recomienda exploración quirúrgica; Grado IV: Se debe considerar como masa renal maligna por lo que se debe realizar cirugia radical). El mismo autor en 1997modificó la clasificación añadiendo una nueva categoría la II F, en la que encuadrar a los quistes no lo suficientemente complejos para etiquetarlos como quiste renal III , pero en los que se aconseja realizar seguimiento radiológico periódico ${ }^{2}$.

No hay ninguna dificultad en etiquetar según los hallazgos radiológicos a los quistes en la categoría I de Bosniak, que son aquellos definidos como quistes simples en los que no se requiere ni seguimiento ni tratamiento alguno, a no ser que se asocie sintomatología generalmente por compresión y por otra parte a los pacientes con quistes grado IV (tumor quístico maligno) que obliga a tratamiento exerativo radical de entrada.

La dificultad radica en etiquetar un quiste renal como grado II (quiste moderadamente complejo pero aparentemente benigno) o grado III (quiste más atípico con signos de posible malignidad a descartar o confirmar con estudio histológico) y sus implicaciones a la hora de decidir el tratamiento o actitud a realizar. Según el propio Bosniak, en caso de duda, se debe considerar el quiste renal como grado III y aconseja la exploración quirúrgica ${ }^{3}$

No obstante y con la aparición de la cirugía laparoscópica puede cambiar la estrategia a seguir, según nuestro criterio, en el manejo de los pacientes con quistes renales grado IIF y grado III, no siendo tan importante la diferenciación en una clase o en otra, ya que ante la disminución de la morbilidad que se consigue con la misma, se podría aconsejar la realización de quistectomía laparoscópica en los pacientes con grado IIF (sobre todo ante lesiones quísticas de gran tamaño, en pacientes jóvenes o de mediana edad, preocupados por la naturaleza de su lesión quistíca) y grado III de Bosniak.
En el caso de lesiones claramente sugestivas de ser quistes renales grado II F, en pacientes añosos y en lesiones de pequeño tamaño, se aconseja TAC de control a los 6 meses del diagnóstico inicial y al año, con controles posteriores anuales ${ }^{3}$.

En estudios recientes tras quistectomía laparoscópica por quistes grado II de Bosniak se ha hallado una no despreciable incidencia de Carcinoma de células claras asociado al mismo, entre un $11 \%$ de los pacientes según Santiago ${ }^{4}$ y un $22 \%$ según Spaliviero ${ }^{5}$. En una revisión bibliográfica reciente ${ }^{6}$ se determina el hallazgo de lesiones malignas en el 18,5\% de los pacientes clasificados en la categoría II, así como en un $33 \%$ de los pacientes clasificados como quistes renales tipo III, lo que nos obliga a pensar en el riesgo evidente, tanto de infraestadiaje (en el caso de no realizar exploración quirúrgica en los pacientes clasificados como quiste renal tipo II), como realizar un sobretratamiento en los pacientes clasificados como quiste renal tipo III.

El quiste renal grado III de Bosniak, se trata de un quiste renal maligno entorno el $50 \%$ de los pacientes según algunos autores ${ }^{7}$, por lo que se beneficiaria de una cirugía radical (Nefrectomía radical) pero en un 50\% ésta sería innecesaria (alta tasa de sobretratamiento). En el caso de exploración quirúrgica convencional (Cirugía abierta-Lumbotomia o vía transabdominal), con la idea de realizar una exploración quirúrgica con valoración del quiste renal, en numerosas ocasiones la nefrectomía es el resultado de la misma con independencia de los resultados hallados; no obstante hasta hace poco la exploración quirúrgica por cirugía abierta con nefrectomía parcial o radical según los hallazgos era el tratamiento de elección en los pacientes con quiste renal grado III de Bosniak.

Actualmente se está generalizando la aplicación de la cirugía laparoscópica en los pacientes con quistes renales tipo III de Bosniak ${ }^{8}$. La técnica utilizada consiste en la exéresis de la pared del quiste remitiéndola a estudio per-operatorio al servicio de anatomía-patológica y fulguración de la base del quiste, aunque en casos de dudas de malignidad del quiste se deberían previamente tomar muestras de la base. 
En dependencia de los hallazgos anatomopatológicos (estudio per-operatorio); en caso de malignidad se realizará cirugía parcial ${ }^{4}$ o radical renal laparoscópica. No se ha demostrado un incremento en la incidencia de siembra peritoneal, recurrencia local o metástasis a distancia en los estudios con seguimiento a largo plazo ${ }^{4}$

En los pacientes con quiste renal Grado I (Quiste renal simple) pero con sintomatología atribuida al quiste renal es más controvertido la generalización del uso de la cirugía laparoscópica, pese ser una de las más iniciales aplicaciones de la laparoscopia en urología por su facilidad técnica $^{9-11}$, al existir otras opciones de tratamiento aún menos invasivas como la punción-esclerosis. Como argumentos a favor para la elección de la cirugía laparoscópica está la alta tasa de recidiva (30 \%) con la punción-esclerosis así como que pudiera pasar inadvertida lesión maligna al no obtener muestra para estudio anatomopatológico.

En caso de exéresis vía laparoscópica de quistes renales Grado I se aconseja estudio per-operatorio de la pared del quiste, ante la descripción excepcional de posible neoplasia maligna en la pared del quiste renal simple sintomático extirpado $^{12}$ e incluso se ha descrito la diseminación neoplásica en la evolución a corto plazo tras la decorticación laparoscópica de un quiste renal simple ${ }^{13}$.

Concluimos aconsejando, dada la mínima morbilidad asociada, la exéresis laparoscópica de toda lesión quística compleja o indeterminada grado III, continuando con cirugía parcial o radical renal según hallazgos peroperatorios. En los pacientes con quiste renal tipo IIF se debería individualizar la indicación quirúrgica; aunque en pacientes jóvenes preocupados con la posible malignidad y más si tenemos en cuenta la posibilidad (en torno el $18 \%$ de ser una lesión maligna) se debería considerar la posibilidad de realizar exploración quirúrgica laparoscópica, según nuestro criterio, teniendo especial cuidado en la revisión cuidadosa de las imágenes radiológicas preoperatorias, los hallazgos intraoperatorios y el obligatorio estudio de las muestras obtenidas (Pared quística/líquido) para que no pase inadvertida ninguna lesión tumoral asociada.

\section{REFERENCIAS}

1. Bosniak MA. The current radiological approach to renal cysts. Radiology. 1986;158(1):1-10.

2. Bosniak MA. Diagnosis and management of patients with complicated cystic lesions of the kidney. Am J Roentgenol 1997; 169(3):819-821.

3. Bosniak MA. The use of the Bosniak Classification System for Renal Cysts and Cystic Tumors. J Urol. 1997;157(5): 1852-1853.

4. Santiago L, Kaswick J, Belmann GC. Laparoscopic evaluation of indeterminate renal cysts: long-term follow-up. Urology 1998;52(3):379-383.

5. Spaliviero M, Herts BR, Magi-Galluzzi C, Xu M, Desai MM, Kaouk JH, et al. Laparoscopic partial nephrectomy for cystic masses. J Urol. 2005; 174 (2):614-619.

6. Warren KS, MC Farlane J. The Bosniak classification of renal cystic masses. BJU international 2005;95(7)939-942.

7. Wolf JS Jr. Evaluation and management of solid and cystic renal masses. J Urol. 1998;159(4):1120-1133.

8. Belman GC, Yamaguchi R. Kaswick J. Laparoscopic evaluation of indeterminate renal cysts. Urology 1995;45: 1066-1072.

9. Stoller ML, Irby PB, Osman M. Laparoscopic marsupialization of a simple renal cyst. J Urol. 1993;150(5 Pt 1):14861490.

10. Pearle MS, Traxer O, Cadeddu JA. Renal cystic disease. Laparoscopic Management Urol Clin North Am. 2000; 27 (4):661-664

11. Zuluaga Gomez A, Arrabal Martin M, de la Fuente Serrano A, Mijan Ortiz JL, Martinez et al. Tratamiento laparoscópico de los quistes renales simples: Indicaciones y revisión bibliográfica. Arch Esp Urol 1995;48(3):284-290.

12. Rubenstein SC, Hulbert JC, Pharand D, Schuessler W, Vancaille TG, Kavoussi LR. Laparoscopic ablation of symptomatic renal cysts. J Urol. 1993;150(4):1103-1106.

13. Meng MV, Grossfeld GD, Stoller ML. Renal Carcinoma after laparoscopic cyst decortication. J Urol.2002;167(3): 1396-1398.

Dr. J. Benejam Gual.

E-mail: jmbenejam@hospitalmanacor.org

(Trabajo recibido el 2 de noviembre de 2005) 